\title{
Muscular performance characterization in athletes: a new perspective on isokinetic variables
}

Giovanna M. Amaral ${ }^{1}$, Hellen V. R. Marinho ${ }^{1,2}$, Juliana M. Ocarino ${ }^{1}$, Paula L. P. Silva ${ }^{1}$, Thales R. de Souza ${ }^{1}$, Sérgio T. Fonseca ${ }^{1}$

\begin{abstract}
Background: Isokinetic dynamometry allows the measurement of several variables related to muscular performance, many of which are seldom used, while others are redundantly applied to the characterization of muscle function. Objectives: The present study aimed to establish the particular features of muscle function that are captured by the variables currently included in isokinetic assessment and to determine which variables best represent these features in order to achieve a more objective interpretation of muscular performance. Method: This study included 235 male athletes. They performed isokinetic tests of concentric knee flexion and extension of the dominant leg at a velocity of $60 \%$ s. An exploratory factor analysis was performed. Results: The findings demonstrated that isokinetic variables can characterize more than muscle torque production and pointed to the presence of 5 factors that enabled the characterization of muscular performance according to 5 different domains or constructs. Conclusions: The constructs can be described by torque generation capacity; variation of the torque generation capacity along repetitions; movement deceleration capacity; mechanical/physiological factors of torque generation; and acceleration capacity (torque development). Fewer than eight out of sixteen variables are enough to characterize these five constructs. Our results suggest that these variables and these 5 domains may lead to a more systematic and optimized interpretation of isokinetic assessments.
\end{abstract}

Keywords: physical therapy; muscle strength dynamometer; knee joint; isokinetics; factor analysis.

\section{HOW TO CITE THIS ARTICLE}

Amaral GM, Marinho HVR, Ocarino JM, Silva PLP, Souza TR, Fonseca ST. Muscular performance characterization in athletes: a new perspective on isokinetic variables. Braz J Phys Ther. 2014 Nov-Dec; 18(6):521-529. http://dx.doi.org/10.1590/ bjpt-rbf.2014.0047

\section{Introduction}

Over the last decades, the technology of isokinetic devices has improved ${ }^{1,2}$. In order to achieve a more thorough description of muscular performance, new variables began to be calculated and included in the assessment reports generated by these devices ${ }^{1}$. However, only a few of these variables have been explored from scientific and clinical perspectives. For example, peak torque has been the most widely reported and discussed approach to the characterization of muscular performance for several years ${ }^{1,3,4}$.

Isokinetic assessments of muscle function are widely used to identify specific deficits, or to assess the results of interventions. Some authors have discussed the relevance and meaning of each variable included in isokinetic assessments ${ }^{1,4-6}$. Some publications reported on variables such as Total Work, Fatigue Index and Power, in addition to Peak Torque ${ }^{6,7}$. However, little is known about the associations among such variables, as well as the individual contribution of each variable to the characterization of muscular performance. A better understanding of these aspects might help to establish which variables measure similar features of muscle function and which variables best represent particular features of performance. Such understanding would allow the report of variables in a uniform and rational manner. Therefore, the aims of the present study were to identify the specific features of muscle function that are represented by the variables currently available in isokinetic assessments and to determine which variables best represent these features in order to develop a more objective assessment of muscular performance.

\footnotetext{
${ }^{1}$ Programa de Pós-graduação em Ciências da Reabilitação, Universidade Federal de Minas Gerais (UFMG), Belo Horizonte, MG, Brazil 


\section{Method}

\section{Subjects}

Preseason isokinetic assessment reports of knee joint flexion-extension concentric motions at $60 \%$ were selected from the laboratory's database. The reports showing a documented history of lower limb injury or symptoms were excluded and only data from the dominant limb were included. The sample included 235 male elite athletes (soccer and volleyball players) with mean age $23.07 \pm 4.84$ years, mean height $1.83 \pm 8.09$ meters and mean body weight $78.18 \pm 9.33 \mathrm{Kg}$. All athletes were, at the time of the evaluation, active in their professional team. The present study was approved by the Ethics Committee of Universidade Federal de Minas Gerais (UFMG), Belo Horizonte, MG, Brazil (approval number 01748412.0.0000.5149), and all athletes signed an informed consent form.

\section{Procedures}

The procedure was explained and the lower limb dominance was determined by asking the athlete which leg he uses to kick a ball. The athletes performed a warm-up consisting of exercises on an ergometric bicycle for 5 minutes. Next, the athletes were placed on the isokinetic dynamometer (Biodex Multi-joint System 3, Biodex Medical Systems Inc, Shirley, NY, USA) in a sitting position with hip flexion of $85^{\circ}$ and the equipment axis aligned with the lateral condyle of the femur. The arms were placed along the sides of the body, the trunk was stabilized against the backrest using the chair belts, the thigh of the tested limb was fixed against the seat by means of a belt, and the contralateral limb was allowed to hang free. The tested leg was weighted to correct for the effects of gravity on the torque measured, according to the specifications of the Biodex Manual. To assess muscular performance, the participants were asked to perform alternating concentric contractions of the knee flexors and extensors within a range of motion of $85^{\circ}\left(90^{\circ}\right.$ to $5^{\circ}$ of flexion). During the test, the participants were instructed to keep the maximum force throughout the entire range of motion. In addition, they were encouraged to go faster and never stop until the end of the assessment. The participants were allowed to familiarize themselves with the procedures before actual testing by performing 3 repetitions of the tested motion. Then they performed a set of 5 repetitions at $60 \%$. When the Coefficient of Variation (CV) of the Peak Torque was higher than $10 \%{ }^{8}$, the athlete was allowed to rest and the set was repeated.

\section{Variables selection}

Sixteen variables available in the Comprehensive Evaluation Reports generated by Biodex Software were selected to be included in this study: Peak Torque, Time to Peak Torque, Angle of Peak Torque, Torque at $30^{\circ}$, Torque at $0.18 \mathrm{~s}$, Coefficient of Variation, Maximum Work, Maximum Work Repetition Number, Total Work, Work Last Third, Work First Third, Work Fatigue Percentage, Average Power, Acceleration Time, Deceleration Time, and Average Peak Torque. The windowing option was turned on to guarantee that only the isokinetic portion (above $70 \%$ of the preset speed) of the test was used. Peak Torque and Maximum Work normalized by bodyweight were not included in the analysis, since normalization would make the results dependent on the individual's mass. Another variable not used in the present study was the Agonist:antagonist ratio, as it does not pertain to the assessment of a specific muscle group.

\section{Statistical analysis}

The present study used an exploratory factor analysis to identify the factors that could accurately characterize muscular performance. This approach assumes the presence of associations and redundancy among the variables included in the isokinetic report. Factor analysis is a set of statistical techniques used to explain the relationship between original observed variables and non-observed variables (factors). Therefore, the number of factors identified is lower than the number of original variables analyzed. Each factor characterizes one theoretical aspect (construct) of muscular performance.

Initial exploratory factor analysis with varimax rotation was performed with the SPSS 15.0 statistical software (SPSS Inc., Chicago, IL, USA). The factors that exhibited an eigenvalue $>1$ were maintained. The Kaiser-Meyer-Olkin (KMO) measure of sampling adequacy and Bartlett's test of sphericity were run to confirm the adequacy of factor analysis. The variables with communality values (proportion of common variance) lower than 0.6 , as well as those with cross loadings over 0.4 , were excluded from the analysis. These variables were excluded successively, and a new factor analysis was performed following the removal of each variable until the goodness-of-fit of the reduced model was attained.

In order to identify outliers for each factor of the reduced model, regression scores were computed for each individual. Following the removal of the outliers in these scores, the final exploratory factor 
analysis was performed. To validate the model relative to the knee extension torque curve data, the sample was randomly divided into 2 subsamples ("split-sample" method), and factor analysis was performed in each subsample to assess whether the initial factor structure was maintained. Finally, to investigate the capacity of generalization of the final factor structure, a second exploratory factor analysis, which included all the variables used in the first analysis, was performed using the knee flexion torque curve data. The similarity between the factor structures generated based on the knee extension and flexion data was assessed by means of Tucker's congruence coefficient.

\section{Results}

Upon initial exploratory analysis $(\mathrm{n}=235)$, Bartlett's test of sphericity was significant $(\mathrm{p}<0.0001)$, and the KMO measure of sampling adequacy was 0.700 , which indicated that factor analysis was appropriate for the data in the present study. These results pointed to the presence of 5 factors that clearly represented different features of muscular performance, and we chose to maintain this initial (5-factor) structure in the subsequent analyses (Table 1).

Application of the procedures to reduce the number of variables in the model resulted in the exclusion of 5 variables. The Coefficient of Variation was the first variable to be excluded (communality $=0.522$ ). Next, the variables Torque at $30^{\circ}$, Time to Peak Torque, Average Power, and Peak Torque at $0.18 \mathrm{~s}$ were successively excluded (cross loading $>0.4$ ). Following the identification and removal of outliers of the resultant scores $(n=219)$, the reduced model of exploratory factor analysis of the knee extension data explained $90.746 \%$ of the total variability of the data. The KMO value was 0.723, and Bartlett's test of sphericity was significant $(p<0.0001)$, indicating that factor analysis was appropriate for the investigated dataset. The variables exhibited adequate communality values (Table 2 ).

Factor analysis of the 2 randomized subsamples (n1=110, n2=109) exhibited KMO values of 0.698 and 0.683 , respectively. Bartlett's test of sphericity was significant $(p<0.0001)$ in both samples. The total explained variance of the data in these subsamples was $91.288 \%$ and $90.537 \%$, respectively (Table 3). These 2 analyses converged towards the

Table 1. Factor structure of knee extensor isokinetic assessment data disclosed by the initial exploratory factor analysis.

\begin{tabular}{|c|c|c|c|c|c|c|}
\hline \multicolumn{7}{|c|}{ Factors } \\
\hline Variables & 1 & 2 & 3 & 4 & 5 & Communality \\
\hline Maximum Work & 0.976 & 0.042 & 0.110 & -0.071 & -0.073 & 0.977 \\
\hline Total Work & 0.961 & 0.042 & 0.036 & 0.005 & -0.123 & 0.943 \\
\hline Work Last Third & 0.944 & 0.062 & -0.163 & -0.137 & -0.106 & 0.952 \\
\hline Work First Third & 0.929 & 0.037 & 0.260 & 0.025 & -0.155 & 0.957 \\
\hline Peak Torque & 0.883 & -0.156 & -0.023 & -0.081 & 0.354 & 0.937 \\
\hline Average Peak Torque & 0.865 & -0.190 & -0.138 & -0.072 & 0.337 & 0.922 \\
\hline Average Power & 0.787 & -0.216 & -0.150 & -0.156 & $0.421 * *$ & 0.890 \\
\hline Acceleration Time & 0.082 & 0.865 & -0.020 & 0.098 & 0.277 & 0.841 \\
\hline Torque at $0.18 \mathrm{~s}$ & $0.400 * *$ & -0.824 & -0.049 & 0.030 & 0.290 & 0.927 \\
\hline Time to Peak Torque & 0.113 & 0.669 & 0.143 & -0.389 & $-0.476^{* *}$ & 0.859 \\
\hline Work Fatigue Percentage & -0.101 & -0.052 & 0.795 & 0.312 & -0.089 & 0.750 \\
\hline $\begin{array}{l}\text { Maximum Work } \\
\text { Repetition Number }\end{array}$ & -0.035 & -0.019 & -0.749 & 0.167 & 0.230 & 0.643 \\
\hline Coefficient of variation & 0.045 & 0.087 & 0.696 & 0.071 & 0.149 & $0.522 *$ \\
\hline Angle of Peak Torque & -0.004 & -0.107 & 0.140 & 0.940 & 0.027 & 0.916 \\
\hline Torque at $30^{\circ}$ & $0.601 * *$ & -0.210 & -0.035 & -0.680 & -0.098 & 0.878 \\
\hline Deceleration Time & -0.033 & -0.001 & 0.045 & 0.018 & -0.830 & 0.692 \\
\hline $\begin{array}{l}\text { Percentage of Explained } \\
\text { Variance }(\%)\end{array}$ & $39.6 \%$ & $12.9 \%$ & $11.7 \%$ & $10.6 \%$ & $10.3 \%$ & \\
\hline
\end{tabular}

$*$ Communality $<0.6 ; * *$ Cross loading $\geq 0.4$. 
Table 2. Factor structure of knee extensor isokinetic assessment data disclosed by the final exploratory factor analysis.

\begin{tabular}{|c|c|c|c|c|c|c|}
\hline \multicolumn{7}{|c|}{ Factors } \\
\hline Variables & $\begin{array}{c}\text { Torque } \\
\text { Generation } \\
\text { Capacity }\end{array}$ & $\begin{array}{c}\text { Variation } \\
\text { in Torque } \\
\text { Generation } \\
\text { Capacity }\end{array}$ & $\begin{array}{c}\text { Movement } \\
\text { Deceleration } \\
\text { Capacity }\end{array}$ & $\begin{array}{c}\text { Mechanical/ } \\
\text { Physiological } \\
\text { Factors } \\
\text { of Torque } \\
\text { Generation }\end{array}$ & $\begin{array}{c}\text { Acceleration } \\
\text { Capacity }\end{array}$ & Communality \\
\hline Maximum Work & 0.977 & 0.077 & 0.060 & -0.043 & 0.017 & 0.966 \\
\hline Total Work & 0.958 & 0.011 & 0.093 & 0.018 & -0.005 & 0.927 \\
\hline Work Last Third & 0.935 & -0.186 & 0.078 & -0.155 & 0.022 & 0.940 \\
\hline Work First Third & 0.935 & 0.258 & 0.095 & 0.042 & -0.016 & 0.952 \\
\hline Peak Torque & 0.883 & -0.095 & -0.308 & -0.064 & 0.044 & 0.889 \\
\hline $\begin{array}{l}\text { Average Peak } \\
\text { Torque }\end{array}$ & 0.859 & -0.172 & -0.314 & -0.072 & 0.023 & 0.871 \\
\hline $\begin{array}{l}\text { Work Fatigue } \\
\text { Percentage }\end{array}$ & -0.096 & 0.812 & 0.031 & 0.365 & -0.069 & 0.808 \\
\hline $\begin{array}{l}\text { Maximum } \\
\text { Work Repetition } \\
\text { Number }\end{array}$ & -0.047 & -0.854 & -0.074 & 0.190 & -0.108 & 0.784 \\
\hline $\begin{array}{l}\text { Deceleration } \\
\text { Time }\end{array}$ & -0.027 & 0.073 & 0.960 & -0.023 & 0.031 & 0.929 \\
\hline $\begin{array}{l}\text { Angle of Peak } \\
\text { Torque }\end{array}$ & -0.073 & 0.041 & -0.020 & 0.956 & -0.024 & 0.923 \\
\hline $\begin{array}{l}\text { Acceleration } \\
\text { Time }\end{array}$ & 0.024 & 0.045 & 0.028 & -0.028 & 0.995 & 0.993 \\
\hline $\begin{array}{l}\text { Percentage } \\
\text { of Explained } \\
\text { Variance }(\%)\end{array}$ & $46.9 \%$ & $14.0 \%$ & $10.5 \%$ & $10.2 \%$ & $9.2 \%$ & \\
\hline
\end{tabular}

same structure in the final model, which therefore supported its validation.

In the exploratory factor analysis of the knee flexion data, Bartlett's test of sphericity was also significant $(\mathrm{p}<0.0001)$, the KMO value was 0.718 , and the explanatory percentage was $91.322 \%$ (Table 4). Tucker's congruence coefficient between the flexion model and the final extension model was 0.95 , thus indicating high similarity between models. These results demonstrate the capacity of generalization of the final model obtained from the knee extensor isokinetic assessment data to the knee flexor isokinetic assessment data at $60 \%$ s.

\section{Discussion}

The results indicated that the set of variables included in knee isokinetic assessment reports could be represented by 5 factors, which together explained more than $90 \%$ of the variance in data. On the one hand, the results indicate much redundancy in the information provided by the variables currently included in isokinetic assessments; on the other, they indicate that 5 different domains of muscular performance are represented by this set of variables. These domains were defined as torque generation capacity, variation in torque generation capacity along repetitions, movement deceleration capacity, mechanical/physiological factors of torque generation, and acceleration capacity (torque development). The identification of these domains should enable a more systematic and optimized interpretation of the data in isokinetic assessments.

Five variables were not included in the final model. The CV had a low communality with the other variables, which is due to the fact that this variable was controlled in our study. The remaining variables (Time to Peak Torque, Torque at $30^{\circ}$, Torque at $0.18 \mathrm{~s}$, and Average Power) had cross loading $>0.4$ for more than one factor (i.e. they bring ambiguous information to test interpretation). For example, Time to Peak Torque and Torque at $30^{\circ}$ depend on multiple attributes, such as the individual's capacity to produce torque and to accelerate the limb, as well 


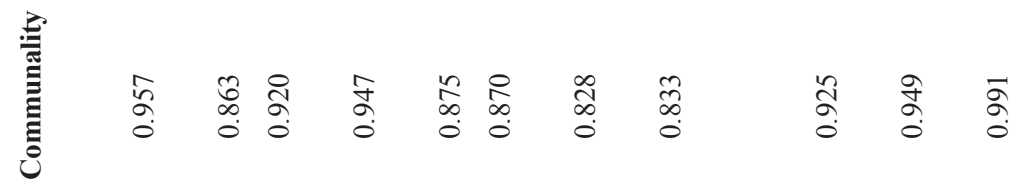

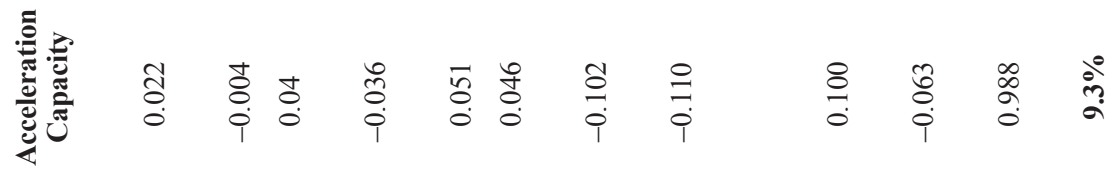

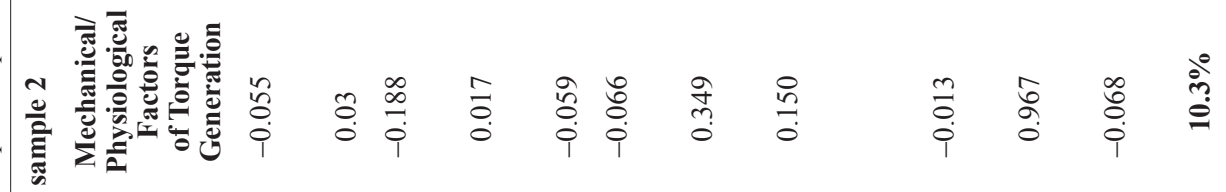

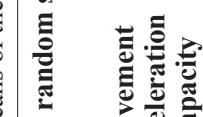

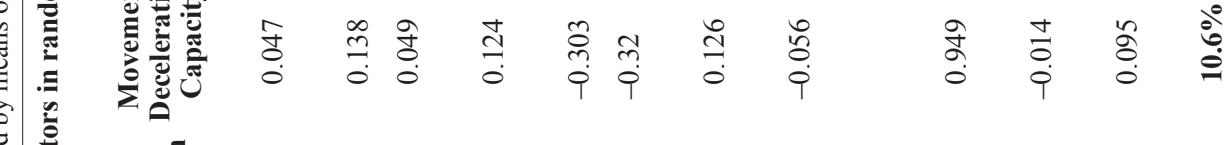

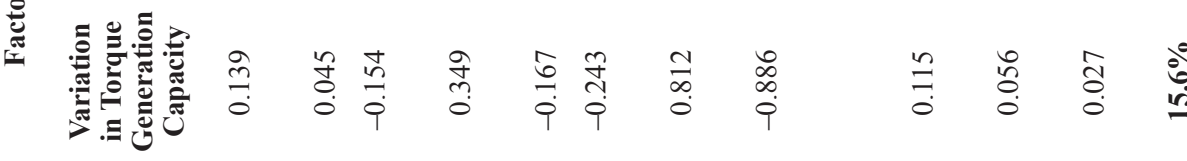

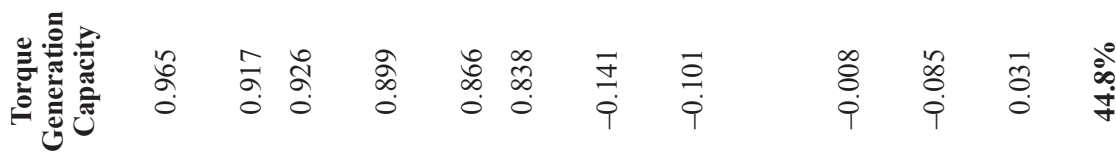

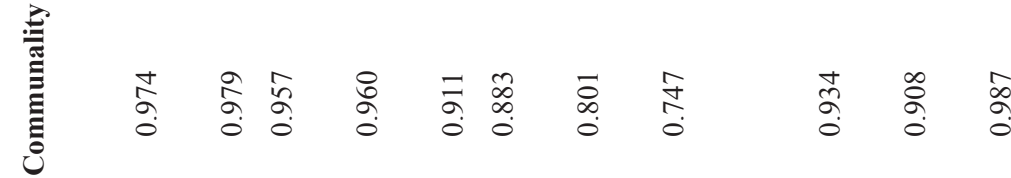

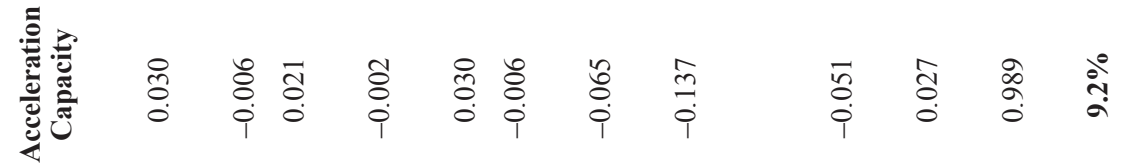

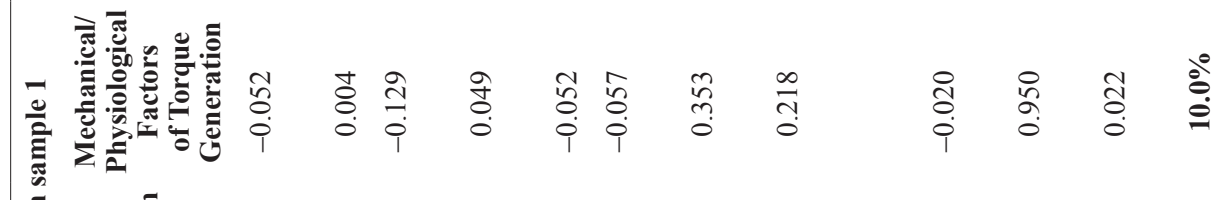

흠

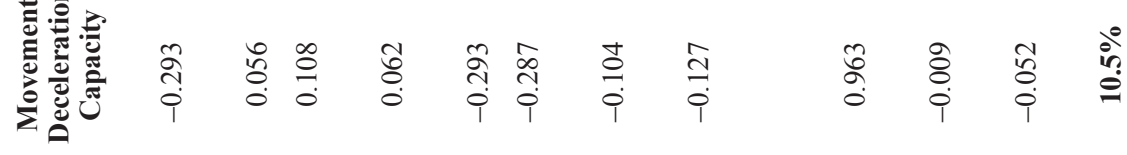

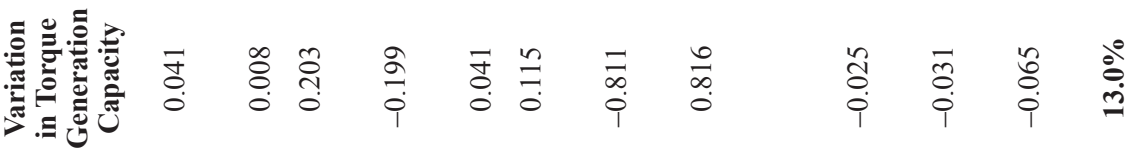

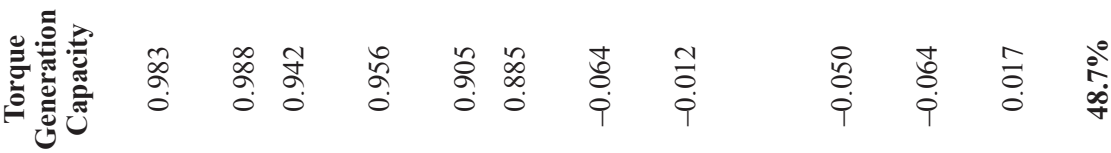

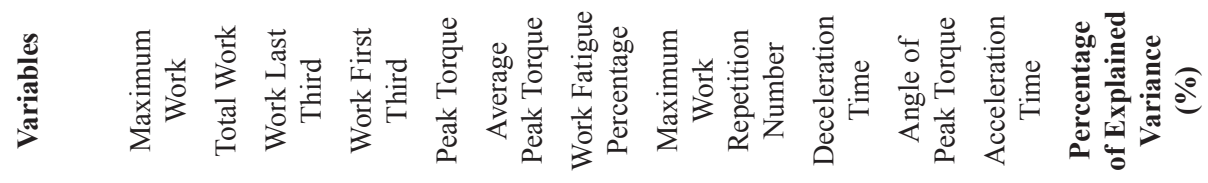


Table 4. Factor structure of knee flexor isokinetic assessment data disclosed by the exploratory factor analysis.

\begin{tabular}{|c|c|c|c|c|c|c|}
\hline \multicolumn{7}{|c|}{ Factors } \\
\hline Variables & $\begin{array}{c}\text { Torque } \\
\text { Generation } \\
\text { Capacity }\end{array}$ & $\begin{array}{c}\text { Variation } \\
\text { in Torque } \\
\text { Generation } \\
\text { Capacity }\end{array}$ & $\begin{array}{l}\text { Movement } \\
\text { Deceleration } \\
\text { Capacity }\end{array}$ & $\begin{array}{l}\text { Acceleration } \\
\text { Capacity }\end{array}$ & $\begin{array}{c}\text { Mechanical/ } \\
\text { Physiological } \\
\text { Factors } \\
\text { of Torque } \\
\text { Generation }\end{array}$ & Communality \\
\hline Maximum Work & 0.968 & 0.128 & 0.091 & 0.007 & 0.021 & 0.962 \\
\hline Total Work & 0.977 & 0.048 & 0.065 & -0.023 & 0.045 & 0.963 \\
\hline Work First Third & 0.938 & 0.276 & 0.027 & 0.036 & 0.01 & 0.959 \\
\hline Work Last Third & 0.918 & -0.224 & 0.183 & -0.101 & 0.111 & 0.948 \\
\hline Peak Torque & 0.912 & -0.007 & -0.126 & -0.132 & -0.115 & 0.879 \\
\hline $\begin{array}{l}\text { Average Peak } \\
\text { Torque }\end{array}$ & 0.912 & -0.068 & -0.128 & -0.16 & -0.114 & 0.891 \\
\hline $\begin{array}{l}\text { Work Fatigue } \\
\text { Percentage }\end{array}$ & -0.04 & 0.845 & -0.248 & 0.157 & -0.2 & 0.841 \\
\hline $\begin{array}{l}\text { Maximum Work } \\
\text { Repetition Number }\end{array}$ & -0.113 & -0.8 & -0.305 & 0.098 & 0.056 & 0.759 \\
\hline Deceleration Time & 0.018 & 0.032 & 0.938 & 0.126 & -0.036 & 0.899 \\
\hline Angle of Peak Torque & -0.019 & -0.195 & -0.04 & 0.046 & 0.969 & 0.981 \\
\hline Acceleration Time & -0.130 & 0.036 & 0.122 & 0.964 & 0.044 & 0.964 \\
\hline $\begin{array}{l}\text { Percentage of } \\
\text { Explained Variance } \\
(\%)\end{array}$ & $48.3 \%$ & $14.0 \%$ & $10.3 \%$ & $9.4 \%$ & $9.3 \%$ & \\
\hline
\end{tabular}

as on muscle length. Thus, the non-inclusion of these variables eliminated redundant information from the test results, as specific aspects of muscle performance were better captured by other variables available in the isokinetic report.

The first factor included the variables that were related to the construct of Torque Generation Capacity. Higher values for these variables were associated with greater torque generation capacity in athletes. This factor captured the largest percentage of the data variability ( $46.9 \%$ of the total variance). The 4 variables that exhibited the greatest factor loading were Maximum Work (0.977), Total Work (0.958), Work First Third (0.935), and Work Last Third (0.935), and these variables also exhibited strong mutual correlation $(>0.90)$. Work, calculated as the area under the force vs. displacement curve, represents the energy spent by muscle exertion during motion (product of torque times angular displacement $)^{4,9,10}$. Maximum Work represents the capacity to generate muscle torque throughout the full range of the movement repetition that exhibits the greatest muscle work production ${ }^{4,9}$. Total Work represents the sum of the work calculated for each repetition ${ }^{9}$, and Work First Third and Work Last Third represent the amount of work performed in those stages of movement in all the test repetitions taken together ${ }^{11}$. This factor was also represented by the variables Peak Torque and Average Peak Torque, with factor loading values of 0.883 and 0.859 , respectively. Peak Torque represents the maximum torque generated at a single point of the entire range of motion among all test repetitions ${ }^{9}$, whereas Average Peak Torque represents the mean value of the maximum torque generated in all 5 repetitions ${ }^{11}$. The high association between Peak Torque and Average Peak Torque was expected, since only tests with small Coefficient of Variation $(<10 \%)$ were allowed in this study. When this criterion is not observed and large variation occurs, lower association between these variables can be expected.

The variable Maximum Work best represented torque generation capacity because it exhibited the greatest factor loading for the first factor, in addition to strong correlation with the variables Total Work, Work First Third, and Work Last Third. Although Peak Torque (factor loading of 0.883 ) has been the variable most widely used in the interpretation of isokinetic assessments, the results of the present study reinforce the need to measure Maximum Work to achieve an accurate characterization of the torque generation capacity. Therefore, the variable 
Peak Torque should not be used alone to represent that construct, as it could lead to errors in the interpretation of the results. The limited ability of Peak Torque to characterize the torque generation capacity of an individual may be related to the fact that it corresponds to the torque generated at a single point of the entire range of motion. Conversely, the variable Maximum Work provides information on the ability of the muscle to generate torque throughout the entire range of motion ${ }^{4}$. Within that context, individuals able to generate high peak torque do not systematically exhibit the greatest values for Maximum Work ${ }^{4}$. Moreover, high Peak Torque values not associated with Maximum Work values may indicate a condition in which the assessed individual is able to generate high torque at a given point but cannot maintain that level of performance throughout the entire range of motion of the knee joint. The results of the present study therefore suggest that both variables (i.e. Maximum Work and Peak Torque) should be included in reports to achieve a thorough characterization of torque generation capacity related to muscular performance ${ }^{12}$.

The second factor identified was represented by the variables Maximum Work Repetition Number $(-0.854)$ and Work Fatigue Percentage (0.812), which were associated with the Variation in Torque Generation Capacity. This factor contributed 14\% of the total explained variance and provided information on the consistency of muscular performance, i.e. the maintenance of torque generation capacity during repetitions. The discrete variable Maximum Work Repetition Number represents the number of the repetition (i.e. 1, 2, 3, 4 or 5) in which the curve exhibited its greatest magnitude ${ }^{11}$. The variable Work Fatigue Percentage represents the percent reduction in the work generated between the first and last thirds of the series of repetitions ${ }^{13,14}$. For lower scores corresponding to this variable, there is generally greater consistency in muscular performance ${ }^{13,14}$. However, this analysis must be performed with caution because this variable was calculated based on only 5 repetitions at a velocity of $60 \%$, and it merely represents the effect of the variation of performance between the beginning and the end of the test. Therefore, in the present study, Work Fatigue Percentage seems to have provided information concerning performance variability. Furthermore, the variable Maximum Work Repetition Number exhibited an inverse correlation with this factor. In other words, the later the Maximum Work repetition occurs, the lower the variability in the response is. Due to the weak correlation between these variables
$(-0.416)$, combined use of both may provide information on the ability to maintain the generated torque during repetitions, which is considered to be indicative of muscle endurance or the neuromuscular ability to keep torque generation constant $t^{13,14}$.

The third factor captured the movement deceleration capacity, represented by the variable Deceleration Time, and contributed to $10.5 \%$ of the total variance. Deceleration Time represents the total time to reduce isokinetic velocity to $0 \% \mathrm{~s}$ at the end of the motion. During an isokinetic testing, the equipment imposes increasing resistance to any torque that attempts to produce movement speeds greater than that selected for the test. Considering that a proper isokinetic assessment requires that the individual produce maximum torque at any point during the test (resulting in an adequate test speed), the Deceleration Time may characterize the capacity of the individual to maintain maximum torque, at the required speed, close to the end of the tested range of motion (in a position in which the muscle is close to active insufficiency). Thus, greater Deceleration Time values may be associated with lower capacity to maintain torque at the extremes of the range of motion. As this variable represents a different condition in comparison to the other variables, it may add relevant information concerning the isokinetic test $\mathrm{t}^{15}$. Although it is seldom reported in studies, this variable represents a domain of muscular performance that should not be neglected.

The fourth factor was represented by the Angle of Peak Torque, which corresponded to $10.2 \%$ of the total explained variance. This factor was associated with the muscle function domain that we defined as Mechanical/Physiological Factors of Torque Generation. The Angle of Peak Torque corresponds to the position of the joint at the moment when Peak Torque is generated ${ }^{7,16-18}$. Therefore, this variable represents the optimal point of the torque vs. angular displacement curve for torque development and is related to the interaction between physiological factors such as optimal muscle length (length-tension relationship) and mechanical factors (changes in the angle of insertion/lever arm during rotatory motion) during performance assessment ${ }^{16,18}$. The interpretation of this variable must take into account not only the absolute values of angulation but also the representation of such angulation relative to the activity of interest. For instance, the Angle of Peak Torque values for the knee flexors and extensors of soccer players were shown to be significantly decreased and increased, respectively, in comparison to cyclists ${ }^{18}$. Furthermore, Angle of Peak Torque 
that does not meet the specific demands of various sports may be associated with a higher incidence of injuries ${ }^{17,19}$.

The fifth factor was associated with the muscular performance domain that we termed acceleration capacity. Acceleration time was the only variable that contributed to this factor, and this variable corresponds to the time needed for the limb to reach the velocity pre-established for the isokinetic test when starting from the rest position. Furthermore, this variable may be considered an indicator of an individual's neuromuscular capacity to develop torque quickly1,20-22. Reduced Acceleration Time values may denote superior muscle fiber recruitment capacity of tested muscles and may be associated with shorter latency for torque generation in such muscles $^{20-22}$. However, the ability to generate high torque values may not suffice to ensure adequate performance, as the speed with which torque is developed must also be taken into account for the characterization of muscular performance. Thus, for a complete assessment, Acceleration Time should be included to address neuromuscular factors related to muscular performance ${ }^{21,22}$. However, it is important to notice that this variable can be more relevant in test conditions involving higher velocities. In these situations, the acceleration demand is more evident and the acceleration capability is crucial for overall performance in the test.

The aforementioned results were reproduced in the analysis of the 2 randomized subsamples generated from the initial sample, the factor structure found in the analysis of knee extensor isokinetic assessment data was therefore fully validated. In addition, this model was also stable during the analysis of the data resulting from isokinetic assessment of another variety of movement (knee flexion). Although there was an inversion in the distribution for the variables Angle of Peak Torque and Acceleration Time in factors 4 and 5 in the analysis of knee flexor isokinetic assessment data (Table 4), the structure of each factor was maintained (i.e. the way in which these variables were distributed among the different factors remained the same), which may be related to the very similar percentages of variance explained by those factors (i.e. $9.4 \%$ and $9.3 \%$, relative to the flexor data). This inversion in the distribution of the variables does not invalidate the structure of the reduced model because the same 5 constructs were still represented. Therefore, muscular performance could be characterized by means of 5 distinct domains.

Factor analysis enabled the identification of 5 different domains that together provided information concerning muscular performance in knee flexionextension isokinetic assessment at a velocity of $60 \%$ in young athletes. Caution is recommended when generalizing the results for different velocities or populations. The results of the present study point to the relevance of the analysis and the inclusion of variables that represent distinct constructs but are often neglected in the interpretation of isokinetic assessments.

\section{Conclusions}

The present study identified five factors that were accurately represented by only a few variables included in isokinetic reports. Each factor represents a different dimension of muscular performance. Our results suggest that Maximum Work should be systematically reported to characterize torque generation capacity. The constructs movement acceleration and deceleration capacity must be more thoroughly explored in future studies, as they provide different information to that supplied by variables describing torque generation capacity. Finally, variability in torque generation capacity and the contribution of mechanical and physiological factors to torque generation may be accurately represented by variables of Maximum Work Repetition Number, Work Fatigue Percentage, and Angle of Peak Torque. Therefore, the use of just a few variables may suffice to capture the full scope of information provided by isokinetic assessments.

\section{Acknowledgements}

To the Pro-Dean's Office for Research of Universidade Federal de Minas Gerais (UFMG), Coordenação de Aperfeiçoamento de Pessoal de Nivel Superior (CAPES), Fundação de Amparo à Pesquisa do Estado de Minas Gerais (FAPEMIG), and Conselho Nacional de Desenvolvimento Cientifico e Tecnológico (CNPq), Brazil.

\section{References}

1. Baltzopoulos V, Brodie DA. Isokinetic dynamometry. Applications and limitations. Sports Med. 1989;8(2):10116. http://dx.doi.org/10.2165/00007256-198908020-00003. PMid:2675256

2. Dvir Z. Physiological and biomechanical aspects of isokinetics. In: Dvir Z. Isokinetics: muscle testing, interpretation, and clinical applications. New York: Churchill Livingstone; 2004. p. 11-25. 
3. Lehnert M, Urban J, Procházka JIH, Psotta R. Isokinetic strength of knee flexors and extensors of adolescent soccer players and its changes based on movement speed and age. Acta Univ Palacki Olomuc, Gymn. 2011;41(2):45-53.

4. Perrin DH, Robertson RJ, Ray RL. Bilateral isokinetic peak torque, torque acceleration energy, power, and work relationships in athletes and nonathletes. J Orthop Sports Phys Ther. 1987;9(5):184-9. http://dx.doi.org/10.2519/ jospt.1987.9.5.184. PMid:18797005

5. Wilk KE. Isokinetic testing: goals, standards and knee test interpretation. In: Biodex Medical System. Biodex Multi-Joint System: clinical resource manual. New York: Biodex Medical System; 1991. p. 5-10.

6. Pincivero DM, Heller BM, Hou SI. The effects of ACL injury on quadriceps and hamstring torque, work and power. J Sports Sci. 2002;20(9):689-96. http://dx.doi. org/10.1080/026404102320219392. PMid: 12200920

7. Cramer JT, Housh TJ, Johnson GO, Weir JP, Beck TW, Coburn JW. An acute bout of static stretching does not affect maximal eccentric isokinetic peak torque, the joint angle at peak torque, mean power, electromyography, or mechanomyography. J Orthop Sports Phys Ther. 2007;37(3):130-9. http://dx.doi.org/10.2519/ jospt.2007.2389. PMid:17416128

8. Brown LE, Whitehurst M. Load range. In: Brown LE, editor. Isokinetics in human performance. Champaign: Human Kinetics; 2000. p. 456.

9. Dvir Z. Hardware, test parameters and issues in testing. In: Dvir Z. Isokinetics: muscle testing, interpretation, and clinical applications. New York: Churchill Livingstone; 2004. p. 25-48.

10. English R, Brannock M, Chik WT, Eastwood LS, Uhl T. The Relationship between lower extremity isokinetic work and single-leg functional hop-work test. J Sport Rehabil. 2006;15:95-104.

11. Biodex Medical System. System 3: structures, formulas and calculations. In: Biodex Medical System. Biodex System 3 advantage software: operations manual. New York: Biodex Medical System; 1991. p. 1-11.

12. Carregaro RL, Cunha RR, Cardoso JR, Pinto RS, Bottaro M. Effects of different methods of antagonist muscles pre-activation on knee extensors neuromuscular responses. Rev Bras Fisioter. 2011;15(6):452-9. http://dx.doi. org/10.1590/S1413-35552011005000028. PMid:22031273

13. De Ste Croix MBA, Deighan MA, Ratel S, Armstrong N. Age- and sex-associated differences in isokinetic knee muscle endurance between young children and adults. Appl Physiol Nutr Metab. 2009;34(4):725-31. http://dx.doi. org/10.1139/H09-064. PMid:19767809

14. Silva JP, Pereira DS, Coelho FM, Lustosa LP, Dias JM, Pereira LS. Clinical, functional and inflammatory factors associated with muscle fatigue and self-perceived fatigue in elderly community-dwelling women. Rev Bras Fisioter. 2011;15(3):241-8. http://dx.doi.org/10.1590/S141335552011000300011. PMid:21829989

15. Ben Moussa Zouita A, Majdoub O, Ferchichi H, Grandy K, Dziri C, Ben Salah FZ. The effect of 8-weeks proprioceptive exercise program in postural sway and isokinetic strength of ankle sprains of Tunisian athletes. Ann Phys Rehabil Med. 2013;56(9-10):634-43. http://dx.doi.org/10.1016/j. rehab.2013.08.003. PMid:24169071

16. Aquino CF, Fonseca ST, Gonçalves GGP, Silva PLP, Ocarino JM, Mancini MC. Stretching versus strength training in lengthened position in subjects with tight hamstring muscles: a randomized controlled trial. Man Ther. 2010;15(1):26-31. http://dx.doi.org/10.1016/j. math.2009.05.006. PMid:19632878

17. Brockett CL, Morgan DL, Proske U. Predicting hamstring strain injury in elite athletes. Med Sci Sports Exerc. 2004;36(3):379-87. http://dx.doi.org/10.1249/01. MSS.0000117165.75832.05. PMid:15076778

18. Brughelli M, Cronin J, Nosaka K. Muscle architecture and optimum angle of the knee flexors and extensors: a comparison between cyclists and Australian Rules football players. J Strength Cond Res. 2010;24(3):71721. http://dx.doi.org/10.1519/JSC.0b013e318197009a. PMid:19816221

19. O'Connor D. Groin injuries in professional rugby league players: a prospective study. J Sports Sci. 2004;22(7):62936. http://dx.doi.org/10.1080/02640410310001655804. PMid: 15370493

20. Jaric S. Changes in movement symmetry associated with strengthening and fatigue of agonist and antagonist muscles. J Mot Behav. 2000;32(1):9-15. http://dx.doi. org/10.1080/00222890009601355. PMid:11008267

21. Chen WL, Su FC, Chou YL. Significance of acceleration period in a dynamic strength testing study. J Orthop Sports Phys Ther. 1994;19(6):324-30. http://dx.doi.org/10.2519/ jospt.1994.19.6.324. PMid:8025571

22. van Cingel RE, Kleinrensink G, Uitterlinden EJ, Rooijens PPGM, Mulder PGH, Aufdemkampe G, et al. Repeated ankle sprains and delayed neuromuscular response: acceleration time parameters. J Orthop Sports Phys Ther. 2006;36(2):72-9. http://dx.doi.org/10.2519/ jospt.2006.36.2.72. PMid:16494074

\section{Correspondence}

Giovanna Mendes Amaral

Rua Oscar Trompowisky, 1275/202, Grajaú

CEP 30431-177, Belo Horizonte, MG, Brasil

e-mail: giovannamamaral@gmail.com 